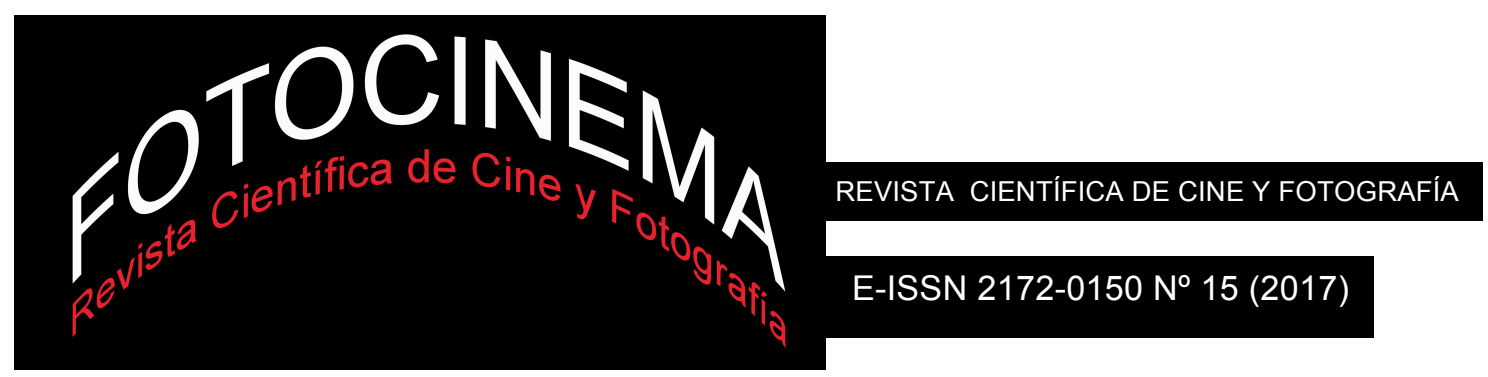

\title{
EXPERIMENTACIONES ENTRE CINE Y FOTOGRAFÍA. UNA CONVERSACIÓN CON BLANCA VIÑAS Y ALBERT ALCOZ
}

\author{
EXPERIMENTS BETWEEN CINEMA AND PHOTOGRAPHY. \\ AN CONVERSATION WITH BLANCA VIÑAS AND ALBERT ALCOZ
}

Sara Donoso

Universidad de Santiago de Compostela, España saradonosocalvo@gmail.com

Trabajando en el campo de la fotografía y el cine experimental respectivamente, Blanca Viñas y Albert Alcoz combinan las potencialidades de cada lenguaje en sus proyectos comunes; film performances donde exploran las posibilidades de la imagen desde el propio aparato fílmico. Estrechando los vínculos entre cine y fotografía, sus proyecciones se fijan en las cualidades del medio para abrir un diálogo con disciplinas como el sonido o la pintura, obteniendo múltiples relaciones estilísticas donde la experimentación plástica predomina sobre el contenido narrativo.

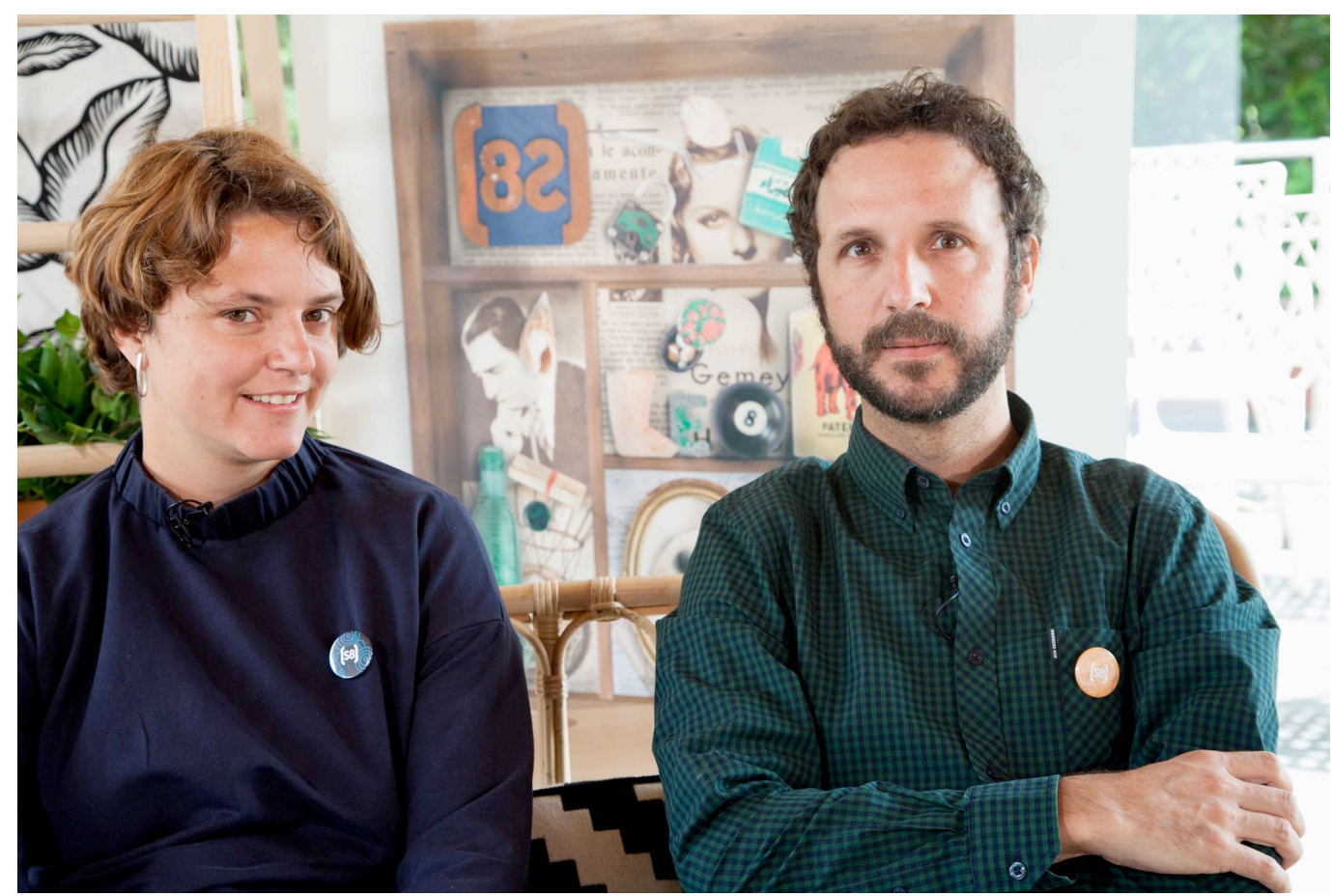


Con motivo de la film performance La noche inventada, que pudimos ver en la octava edición del (S8) Mostra de Cinema Periférico de A Coruña, converso con los artistas sobre sus experiencias de cine en vivo, sobre su práctica creativa y sus modos de entender el arte.

Contáis con una trayectoria individual como artistas, empleando lenguajes y planteamientos discursivos diferentes, pero también aunáis esfuerzos $y$ experiencias para realizar diferentes film performances. ¿En qué punto convergen vuestros trabajos y cuáles son las claves de esta puesta en común?

Albert Alcoz: Básicamente la proyección. Cuando Blanca hace fotografías las suele exponer o utilizar para portadas de disco o revistas y cuando yo hago películas procuro moverlas por festivales individualmente. El punto de unión es lo que llamamos ahora performance o directo fílmico, una combinación de proyecciones de diapositivas con películas. Ese es el punto de unión a nivel de contexto, luego a nivel estético también hay ciertas similitudes.

Blanca Viñas: Sí, de hecho no pensamos en otra finalidad que no sea la proyección en nuestro trabajo común.

AA: Claro, cuando trabajamos piezas más abstractas de pintura sobre celuloide o diapositivas la finalidad es mostrarlo en proyecciones fílmicas en directo. Las cuestiones más personales las movemos cada uno por su lado, pero convergen a partir del momento en que hay similitudes técnicas y tenemos que plantearnos cómo armar 45 minutos coherentes de proyección. De todos modos, siempre tenemos en mente poder desplegar este mismo proyecto en forma de exposición o libro ilustrado.

\section{¿Cuáles diríais que son esas similitudes técnicas?}

BV: El hecho de usar filtros de colores en Super 8 o en 16mm y en fotografía, jugar con el blanco y el negro en positivo y negativo, con filtros prismáticos que deforman la imagen, máscaras internas...

AA: También jugar con múltiples exposiciones, esto lo hacemos a menudo. Es decir, soluciones técnicas más estéticas o abstractas que huyen un poco de la imagen realista y que están más ligadas a las artes plásticas, sin duda. 
Cuestionamos la fotografía y el cine buscando la abstracción, la repetición, cuestiones estéticas...

BV: Y pensar también de qué manera se perciben estas manipulaciones en la imagen fija y en la imagen en movimiento. La percepción es muy distinta, es interesante usar un filtro de color en una imagen estática y luego ver cómo funciona en el filme.

AA: Nuestros trabajos no son documentales, no tienen puesta en escena ni son ficciones, no hay actores... son registros libres, personales y a veces autobiográficos donde muy a menudo aparece la investigación y la exploración sobre el propio medio que empleamos.

¿Qué significa para vosotros el trabajo colaborativo y qué necesidades os impulsaron a realizar proyectos en común?

AA: Es importante delegar, ambos tomamos las decisiones sin seguir una directriz clara, intentando experimentar.

BV: Y plantear de qué manera se puede funcionar con los dos registros. Por ejemplo, yo propongo algo a Albert y él me dice cómo se puede adaptar cierta estructura o mecanismo en el filme.

AA: Sí. Quizá Blanca es más de tratamiento con los materiales, de buscar alternativas, maquinar texturas, manchas y posibilidades sobre la película.

Ahora quería preguntaros por vuestro trabajo individual. Empiezo por ti, Blanca. Tu formación académica es en el campo de la ingeniería y la gráfica publicitaria, aunque finalmente te decantas por el mundo de la fotografía, en el que te inicias a través de diferentes cursos formativos $y$ terminas convirtiendo en tu profesión. ¿Qué hay de cada una de estas disciplinas en tu práctica creativa?

BV: Los entornos urbanos siempre están muy ligados a la fotografía, la arquitectura en este campo me ha influenciado de alguna manera. Pero nada más, es solo el interés por la geometría, por desconfigurar la arquitectura, por de-construir en vez de construir. Puede que esto lo haya aplicado en mi trabajo pero no conscientemente. En cuanto al diseño gráfico, es cierto que sin darme 
cuenta descubro que puede funcionar para portadas de libros o discos, carteles de festivales... Tiene este lenguaje que funciona muy bien para otros artistas y no tanto para la publicidad más comercial.

Albert, tu trabajo gira en torno al medio cinematográfico desde la investigación, la docencia y la práctica experimental. Has escrito para diversos medios, cuentas con el blog Visionary Film y acabas de publicar el libro Resonancias filmicas. El sonido en el cine estructural (1960-1981). Este doble perfil como teórico y creador aporta un punto de vista más amplio en cuanto a la situación actual del cine experimental. Si pensamos en el propio término experimental, me pregunto por la conveniencia de la etiqueta como fórmula de identificación teórica de cierto tipo de cine o la necesidad de matizar sus posibles expansiones o categorías.

AA: Quizá inicialmente la etiqueta más significativa sería cine de vanguardia. Todo esto sale de la historia de las artes plásticas de los años 10- 20, a partir de las rupturas del cubismo. De qué modo en la pintura se empiezan a trabajar la multiplicidad de los puntos de vista, la ruptura de la representación renacentista y demás consideraciones visuales. Estas cuestiones son aplicadas por las vanguardias históricas: la abstracción, el cubismo, el surrealismo... Los artistas plásticos ven que hay un nuevo medio -el cinematógrafo- que aún no se ha consolidado como medio narrativo y, en este sentido, quizá sea más válido el término "cine de vanguardia". En Estados Unidos lo llaman Avant-Garde Cinema y hay muchos cineastas que no ven nada claro lo de "experimental". De hecho, muchos dicen que no hacen cine experimental porque tienen muy claro lo que hacen, es decir, que no tratan de experimentar, probar o hacer un test con las posibilidades fílmicas. De todos modos, yo creo que el término experimental tiene cierta validez para englobar el cine sin cámara, el cine found footage, el cine más personal, más lírico... y para dejar al margen el cine de ficción, ya que se trata de un cine no narrativo que escapa del cine ortodoxo más tradicional... Pero bueno, como todas las etiquetas tiene su controversia, eso es indudable.

Sí, muchas veces aplicamos etiquetas sin plantearnos hasta qué punto son válidas. 
AA: Sí. Pero las etiquetas a menudo son muy válidas para cierta gente a la hora introducirse en determinados ámbitos. A veces los artistas reniegan de ellas pero esas etiquetas sirven para que el público no iniciado se introduzca en cierto ámbito.

BV: También hay etiquetas más generalistas y más específicas dentro del propio experimental.

AA: Sí, es cierto que hay una escena, cine de vanguardia, cine experimental... Hay un crítico, Scott MacDonald, que le llama Critical Cinema, por otro lado P. Adams Sitney le llama Visionary Film y Amos Vogel le llama Cine Subversivo, Gene Youngblood utiliza el concepto Cine Expandido, otros se decantan por el término Underground... cada uno aplica lo que le parece pero sirve para trazar un panorama general.

Volviendo a vuestro trabajo conjunto, se ponen en diálogo dos disciplinas plásticas diferentes que, sin embargo, muchas veces van de la mano: fotografía y cine. Son dos lenguajes que pertenecen al universo de lo bidimensional pero su naturaleza es muy diferente, se opone la estaticidad al movimiento. Sin embargo, se ha teorizado mucho en torno a las relaciones e influencias entre uno y otro medio. ¿Cómo entendéis, cada uno desde vuestro campo y experiencia, esta simbiosis?

BV: Yo en este caso lo entiendo de una manera muy evidente por el hecho de que es una secuencia de imágenes. En nuestros film performances yo no muestro una única diapositiva sino que son carretes que se han disparado como unidad. Al final el cine también es una secuencia de imágenes.

AA: Hay muchos vínculos. Uno sería el material fotoquímico, tanto fotografía como cine analógico cuentan con unos procesos de exposición a la luz, de revelado... Después está el despliegue del tiempo; la temporalidad. A mí me parece muy interesante el modo en que una fotografía captura un instante concreto y el cine puede capturar el tiempo a diferentes velocidades o ritmos. Una proyección de diapositivas son imágenes fijas que van avanzando y adquieren cierto ritmo y las películas a veces son a 18 fotogramas por segundo, a veces a 24... también varían los ritmos. 
BV: También es interesante nuestra intervención en el tiempo cuando proyectamos. Aunque el trabajo esté ya finalizado, contamos con cierto margen en el momento de la proyección que nos permite jugar con el componente del tiempo, modificar la duración, etc.

Otro elemento que coincide en vuestros trabajos tanto a nivel individual como en la puesta en común es el sonido, que aparece de manera activa en vuestros film performances. Me gustaría saber cómo concebís este aspecto y su relación con la imagen.

AA: La idea es enfatizar los propios materiales que se están desplegando durante la proyección. Los materiales que hacen ruido son los proyectores, por lo que ponemos micros de contacto para poder amplificar esos sonidos. Esta es una estrategia, la otra es el hecho de que el proyector de $16 \mathrm{~mm}$ tiene la opción de reproducir sonido óptico, que se puede realizar sobre el soporte fotoquímico sin herramientas de grabación de sonido, pintando el celuloide o haciendo un tipo de edición donde trabajas el espacio que normalmente ocuparía la banda de sonido óptica. El proyector lee esos grafismos y los transforma en señal acústica. Es un trabajo sobre los materiales, sobre las herramientas. No nos interesa añadir música arbitraria sin justificar su uso, eso yo creo que sería uno de los errores más clamorosos.

Es un poco como señalar la presencia del aparato que permite reproducir la imagen.

AA: Sí. Sería muy fácil tratar de buscar ciertos tonos emocionales para el público en función de músicas. Si que al inicio de La noche inventada mostramos como un collage sonoro de abstracciones pero no existe la voluntad de dirigir al público a ciertas sensaciones mediante la música, más bien es una banda sonora hecha de rupturas constantes.

BV: También el sonido de la diapositiva permite enfatizar la frecuencia del tiempo y del pase de imágenes.

Otro elemento de radical importancia en vuestro trabajo es la pintura. A veces se muestra plasmada sobre el celuloide, abstracta y en movimiento, lejos de su soporte ordinario. Pero lo pictórico no solo aparece cuando empleáis esta técnica sino también en las 
propias imágenes, modificadas a través de filtros de color y otros recursos plásticos que se vinculan con este lenguaje.

AA: Sí, el celuloide pintado proviene de toda esta trayectoria que es el cine sin cámara, hacer películas interviniendo directamente el soporte. Nos interesa la abstracción, no buscamos grafismos concretos sino experimentar con manchas de colores.

BV: Nos interesa la relación que puede existir en una cierta vinculación con la realidad, cómo alguien puede pensar en imágenes microscópicas o espaciales... Cómo de alguna manera el subconsciente te lleva a imaginar la historia de la imagen sin que sea evidente, dejando mucho margen a la imaginación.

AA: Sí está también relacionado con la música visual, todo el cine experimental abstracto es fácilmente identificable con lo micro y lo macro.

Otro punto que os une es el interés por la exploración del medio, traspasando la barrera del modo de representación institucional para alcanzar una experiencia plástica más libre, ligada en muchas ocasiones a la investigación de las posibilidades técnicas de la propia cámara. ¿Es más favorable el formato analógico que el digital a la hora de resaltar estas cualidades?

AA: El formato analógico permite trabajar directamente con las manos con ese material, el formato digital es teclado, pantalla y ratón.

BV: Yo creo que lo más interesante del medio analógico es la sorpresa, el azar que no te da el digital. En el digital hay unas decisiones premeditadas, ya sabes qué vas a hacer, cómo y qué resultado vas a conseguir. En el formato analógico partes de unas nociones previas pero nunca sabes en qué se va a convertir finalmente la pieza.

AA: En el fondo es mucho el ensayo-error. Nuestra práctica artística va mucho en esa línea, de asumir errores, buscar posibilidades plásticas y materiales a través de la experimentación.

Es decir, que valoráis mucho el error. Porque a la hora de obtener una textura o una plástica concreta también se puede conseguir a través de programas digitales. 
AA: Sí, la diferencia es que no puedes manipular directamente la imagen sobre el soporte físico concreto y en el analógico sí. Por otro lado, a mí me cuesta entender cómo funciona la imagen digital para distorsionarla. Al final es conocer las herramientas.

BV: Tienes que conocer el medio para saber qué quieres conseguir. En analógico sabes que es una superficie sensible a la luz y a partir de ahí intervienes.

\section{Y la idea de tocar también está presente, ino? El hecho de estar en contacto con el material a lo largo del proceso...}

AA: Esto que has dicho del carácter procesual es importante. Por un lado está el resultado, es decir, algo que muestras al público y que al final es una fase más. Lo interesante es de qué modo nosotros vamos practicando, es casi más importante el proceso que el objeto final.

BV: La proyección también forma parte del proceso. Cada vez que realizamos estas proyecciones vamos viendo cómo funcionan y pensamos en cómo ir modificándolas.

Aunque vuestros trabajos apuestan por una potencia visual que deja de lado el contenido narrativo habitual, ¿significa esto abandonar cuestiones discursivas en favor de valores plásticos formales?

AA: El concepto existe. Las cuestiones estéticas están pero hay un discurso detrás. Incluso un discurso político porque hay un posicionamiento como artistas. Es decir, hacemos este cine porque existen estos medios, no nos interesa buscar subvenciones para levantar la industria, para hacer un trabajo de ficción, etc. Es un cine pobre, sí, de materiales sencillos, sí, pero es un cine que investiga las posibilidades técnicas y sus potencialidades y ésto es lo que intentamos transmitir a los espectadores. Nuestra propuesta no está relacionada con el tono nostálgico que a menudo se asocia a la recuperación de materiales fílmicos analógicos. A la vez es un cine minimalista, que muy a menudo pide gran implicación por parte del público. Tom Gunning razonaba sobre la noción de participatory film al describir películas que piden una percepción del todo activa por parte de la audiencia. 
BV: También implica descubrimiento. Al final significa ser autodidacta, buscamos seguir formándonos a través de la creación. Nos formamos a través de equivocarnos, explorar y hacer lo que nos apetece.

AA: Indudablemente, asumimos que esto no es nada nuevo, parte de la tradición del arte del siglo XX y de toda la experimentación fotográfica y fílmica y está relacionada con el cine sin cámara, con el cine matérico, con el cine estructural, sistemático, de patrones marcados, el cine métrico... Hay muchas variantes cinematográficas que nosotros recogemos y añadimos a nuestro trabajo creativo.

Otro recurso que está presente en vuestras obras el paisaje, que yo lo entiendo aquí como elemento móvil. ¿Acudís a él desde el paseo más que desde la práctica contemplativa?

BV: Esto nos pasa porque nos apetece ir a pasear y el tener la cámara en mano es la excusa. El paseo forma parte de la práctica artística o de la creación, el ir descubriendo a través del caminar. También es una vía de escape.

AA: La fotografía cuando hace imágenes de escenarios exteriores son estáticas. En el cine lo que yo busco es cierta rítmica, cierto movimiento para jugar con las dinámicas, velocidades y capacidad de transformación de los espacios. Nos interesa mucho un autor que se llama Francesco Careri que tiene un libro titulado Walkscapes: el andar como práctica estética, que habla del caminar y de qué modo se articula el paisaje con el contexto artístico.

En muchas ocasiones pasáis de lo figurativo a lo abstracto muchas veces a través del zoom. De un paisaje reconocido como puede ser un árbol o una montaña a la imagen de sus texturas, de su propia composición en movimiento.

BV: También podría ser al revés pero el hecho de partir de lo figurativo ayuda al público a centrarse, a entender cuál es el inicio. Se parte de algo más accesible a un campo que exige más por parte del espectador.

AA: Al mismo tiempo nos interesa que el espectador no esté manipulado y tenga que pensar ciertas cosas. No es algo hermético. A la vez nuestros film performances tienen un componente documental sutil, hay elementos figurativos que aparecen mientras filmamos y los incorporamos. 
La temática que este año propuso el (S8) participa de esta visión de abrazar lo heterogéneo, la idea de collage en la imagen, de encuentro e incluso de Ready made, esa estrategia de apropiarse de algo ya existente y transformar su significado en un nuevo contexto. ¿Vuestros trabajos transitan en esta línea?

AA: En La noche inventada todo son trabajos visuales originales, no hay nada de reciclaje ni apropiación. Pero en otros trabajos individuales Blanca ha hecho mucho collage y yo he hecho otras piezas de reciclaje, de found footage de otros materiales. Aunque en este caso lo descartamos.

BV: Bueno esto tiene relación con lo que decíamos al principio de que unimos las dos prácticas en un mismo contexto.

AA: Sí pero el found footage es una práctica de recopilación y reconfiguración de materiales preeexistentes. Nosotros no lo hemos hecho aquí. Lo podríamos haber hecho con películas ya existentes y pintarlas encima...

BV: O que yo manipulara lo tuyo y tu lo mío o algo así... pero no es el caso.

Por último, me gustaría pasar a hablar, en términos generales, del contexto en el que se inscribe este tipo de cine. En los últimos tiempos estamos asistiendo a una proliferación de programación de cine en los museos o instituciones artísticas. Sin embargo, es un tema complejo que muchas veces genera polémica en cuanto a los métodos de visualización, los tiempos o las condiciones de exhibición. ¿Cómo veis esta tendencia a la musealización del cine? ¿Qué herramientas o estrategias deberían mejorarse y cuáles creéis que han favorecido la normalización y difusión del cine experimental?

AA: Yo creo que en los últimos años los museos de arte contemporáneo han apostado por el cine experimental. Lo que pasa es que hay una gran diferencia entre la proyección única en la sala de cine y el trabajo expositivo. Un espectador cuando va a una exposición no espera invertir cuatro o cinco horas y muy a menudo muchos de los filmes o vídeos que se exponen, si los sumas, pueden llegar a superar las doce horas. Entonces el espectador se puede frustrar. 
BV: Además puede estar viendo cinco minutos de algo que realmente no es identificativo del filme. Por eso funciona mejor en este caso el festival, donde conoces qué vas a ver, cómo y cuándo se proyecta.

AA: Una de las cosas más interesantes de festivales como el (S8), que promocionan este tipo de cine de vanguardia, es que los autores están presentes y se puede generar un debate después de las proyecciones. De este modo se explicita la ausencia de intermediarios. Por otro lado, los museos hacen una importante labor de difusión y es un modo de ensanchar el tipo de público.

BV: También permite enseñar el trabajo de otra manera, mostrar el fotograma, acercarse al proceso...

AA: Una de las grandes diferencias es de qué modo el espectador está viendo eso. En una sala expositiva el público recorre el espacio mientras que en el cine está sentado y puede permanecer así un buen rato. Una de las soluciones que, por ejemplo, encontró el Whitney Museum de Nueva York fue integrar un cine dentro del mismo espacio expositivo, que funcionara durante los mismos horarios. Durante las exposiciones de cine experimental también había una sala donde se proyectaban en loop los trabajos. Pero bueno es un tema delicado.

\section{En cuanto al papel de la crítica y al propio panorama artístico, ¿qué podríais decirnos de la práctica y presencia de este tipo de cine en la actualidad?}

AA: Yo creo que faltan especialistas, gente que escriba... y se agradece que venga gente a entrevistarte.

BV: Faltaría que se difundiera también en medios más generalistas para acercarlo más al público.

AA: Claro, lo que hacemos es para todos los públicos. Lo raro es el cine narrativo, lo raro es ver a Leonardo DiCaprio haciendo de Napoleón. Lo nuestro es cine sencillo, humilde, personal, cotidiano...

\section{¿Y cómo hacer que el público participe de esta idea?}

AA: Hablando, haciendo presentaciones, coloquios, haciendo ver a la gente que el cine no solo consiste en llenar grandes salas, en tener extras, decenas de técnicos o en esperar varias horas para poder grabar... 
BV: Por ejemplo, durante una de las sesiones de Helga Fanderl en el (S8) lo que hizo fue sacar su cámara, empezar a enseñarnos la herramienta con la que trabaja. Entonces de repente te apetece salir y coger también la cámara. Se trata de hacer el cine accesible.

AA: Y hoy en día con las cámaras digitales alguien se puede expresar con imágenes en movimiento o con fotografías de manera muy sencilla. Yo lo que considero es que alguna gente está muy acomodada y reduce el cine únicamente a la ficción. Quizá falta un poco más de curiosidad, o darle al público ciertas herramientas para ver que hay otros cines y que entiendan que son tan válidos como el cine narrativo. Cuando se enseña cine en las escuelas existe lo que comentabas antes del modo de representación institucional, es una lacra. Primer plano, plano americano, panorámica, travelling... al final son normas que limitan el medio, no lo expanden. El medio es mucho más flexible de lo que la industria cinematográfica dice. En el cine narrativo se invierte mucho dinero y se convierte en una cuestión económica. Pero por suerte también hay muchos cineastas más ligados a las artes plásticas o con una mirada más abierta.

BV: De hecho, lo que nos interesa de nuestro trabajo es que nos permite hacer lo que queremos. Si hubiera alguien detrás que nos dijera "pinta la diapositiva de esta manera”, ya dejaría de tener sentido.

\section{Muchas gracias a los dos. Si queréis añadir algo más...}

AA: Sí, quizás una cosa. Resaltar la idea de juego. Ya lo decía Duchamp: "el arte es un juego entre todas las mujeres y todos los hombres de todas las épocas". Cualquier artista está haciendo referencia a prácticas artísticas anteriores y las modifica a su manera; eso es un juego. Hay unas normas, cada uno se impone las que quiere y a partir de ahí a jugar, sea o no sea industria. También está bien ponerse pautas, a mí por ejemplo me interesa el cine estructural, seguir unos patrones, unas constricciones, o decisiones marcadas sistemáticas y ver hasta dónde puedes llegar a partir de ellas.

BV: Salir de los límites establecidos y cerrar el abanico de posibilidades ayuda a potenciar el trabajo. 
AA: Las limitaciones son potencialidades. Al final por pocos medios que tengas siempre puedes crear algo. Un buen ejemplo sería Joseph Cornell; no tenía nada y hacía películas, las recolectaba, hacía collage... hacía arte.

Cómo citar: Donoso, S. (2017). "Experimentaciones entre cine y fotografía. Una conversación con Blanca Viñas y Albert Alcoz". Fotocinema. Revista científica de cine $\mathrm{y}$ fotografía, $\mathrm{n}^{\mathrm{o}}$ 15, pp. 321-333. Disponible: http://www.revistafotocinema.com/ 